Original Research Article

\title{
A survey of knowledge, attitude and practice of adverse drug reaction monitoring among doctors in Western Odisha region
}

\author{
Kaustav Saha ${ }^{1,2}$, Bhabagrahi Rath ${ }^{1}$, Ratna Agrawal ${ }^{1,3 *}$
}

\begin{abstract}
${ }^{1}$ Department of Pharmacology, V.S.S. Institute of Medical Sciences and Research, Burla, Sambalpur, Odisha, India ${ }^{2}$ Department of Pharmacology, Calcutta School of Tropical Medicine, Kolkata, West Bengal, India ${ }^{3}$ Department of Pharmacology, Late Baliram Kashyap Memorial Government Medical College, Dimrapal, Jagdalpur, Chhattisgarh, India
\end{abstract}

Received: 11 September 2018 Accepted: 05 October 2018

*Correspondence to:

Dr. Ratna Agrawal,

Email: ratna.arang@gmail.com

Copyright: (C) the author(s), publisher and licensee Medip Academy. This is an openaccess article distributed under the terms of the Creative Commons Attribution NonCommercial License, which permits unrestricted noncommercial use, distribution, and reproduction in any medium, provided the original work is properly cited.

\begin{abstract}
Background: Adverse drug reactions (ADRs) are the major cause of drug related morbidity and mortality. Pharmacovigilance is the science that plays an important role in the reduction of ADRs. Voluntary reporting of ADRs by healthcare professionals is an important tool in the success of pharmacovigilance program, but the same are scantly reported due to lack of awareness and knowledge among the physicians. So, the present study was conducted to evaluate the knowledge, attitude and practice (KAP) regarding ADR reporting among healthcare professionals at a tertiary care hospital.

Methods: A questionnaire-based study containing 25 questions (knowledge- 18, attitude -2 and practice- 5) was conducted in 70 prescribers and time allotted to complete it was 1 week. Statistical analysis was done by using Graph Pad Prism version 6.01 .

Results: Out of 70 prescribers, only $50(71.43 \%)$ responded. ADR reporting was considered very important by almost all of them, but actual practice was lacking as only $36 \%$ of consultants had reported any ADR. The higher grading was given to causes most important for reporting were patient safety, to identify safe drug and new ADRs. The main reasons for under-reporting were unavailability of reporting forms when needed, uncertain association and lack of knowledge about reporting procedure.

Conclusions: The prescribers are aware of the importance of ADR reporting, but lack of awareness and knowledge are most common cause of under-reporting. So, there is need of pharmacovigilance awareness program to improve voluntary reporting of ADRs.
\end{abstract}

Keywords: Adverse drug reaction, Attitude and practice, Knowledge, Pharmacovigilance

\section{INTRODUCTION}

Drugs are prescribed for the benefit of the patients, but they can also cause harm to the patient by causing adverse reactions. Even the ancient Indian text like Charaka Samhita (written about 6000 years back) mentions about the adverse reactions of drugs. ${ }^{1}$ Adverse drug reactions are the major causes of hospital admission and in- hospital morbidity and have become important clinical problem and a constant concern of the public healthcare system accounting for up to $5 \%$ of hospital admission, $28 \%$ of emergency visits and $5 \%$ of hospital deaths with associated economic burden. ${ }^{2}$ Therefore, importance of timely 
detection as well as prevention of ADRs cannot be overemphasized.

Currently, India contributes only about 3\% of ADRs reported globally. ${ }^{3}$ The spontaneous or voluntary reporting of ADR is most common method of ADR reporting. But the under reporting and an inability to calculate the incidence of ADRs are the inherent disadvantages of this method. ${ }^{4-6}$ So the causes of under reporting among practitioners are needed to be identified and evaluated so as to improve the reporting. This knowledge, attitude and practice analysis of ADR reporting is a step in this direction.

Knowledge, attitude, practice study related to ADR has not been extensively conducted in India and can vary from place to place. A few studies carried out in India and Nepal have shown poor knowledge, attitude and deficient practices of ADR reporting among the prescribers and health care professionals. ${ }^{7-9}$ Yet, only a limited number of pharmacologists and pharmacists, and that too in a few teaching hospitals and medical colleges in country, have been involved, and perhaps even fewer possess the necessary insight about pharmacovigilance. ${ }^{10}$ There is urgent need to make people aware about pharmacovigilance and to ensure patient safety. So, with this background, this KAP study of pharmacovigilance was conducted.

\section{METHODS}

This was an observational, questionnaire- based study, conducted at V. S. S. Institute of Medical Sciences and Research, Burla, Odisha from October 2016 to December 2016. Prescribers (consultants and post graduate students) from various specialties were enrolled in the study after taking informed consent. A pre validated KAP questionnaire containing a total number of 25 questions (knowledge $=18$, attitude $=2$ and practice $=5$ with their further subdivisions) were distributed among them to obtain information regarding the demographics of respondents, knowledge regarding the ADR reporting system, their attitude towards ADR reporting and the factors that encourage or discourage reporting. ${ }^{11,12}$ They were only asked to mention their age, sex, specialty and qualification, which were used as demographic variables. Prescribers were not required to reveal their identities.

A total number of $70 \mathrm{KAP}$ questionnaires were distributed and time period allotted to complete the form was one week, reminder was given two days after and if forms were misplaced, they were replaced. Procedure and queries were briefly explained to each prescriber personally.

One week after, forms were collected. Those who were not willing to take part in study were excluded. Prescribers were requested to answer as many questions as possible and then questionnaires were evaluated for their completeness and one point was given for every question and for its subdivision (maximum score: 60). The knowledge part was evaluated separately by giving one point to each question. Those whom scored less than 25, were graded as having poor knowledge, score between 25 40 was considered as average/ working knowledge and those who scored above 40, were considered to have adequate knowledge.

\section{Statistical analysis}

The data were analysed using the Microsoft Excel and GraphPad Prism version 6.01. Results were presented as mean with standard error of mean (Mean \pm SEM) and percentage.

\section{RESULTS}

Total 70 sets of questionnaires were distributed among prescribers from different specialties of whom 30 were distributed to consultants and rest were given to post graduate students. Out of 70, only 50 responded, the response rate being calculated was $71.43 \%$. Out of total, 50 respondents 25 were consultants and 25 were post graduate students. The response rate of consultants $(83.3 \%)$ was higher than that of post graduate students $(62.5 \%)$ in our study. The sex ratio was equal in the present study as out of fifty respondents $25(50 \%)$ were males and $25(50 \%)$ were females. Of this, 20 respondents $(40 \%)$ were below 30 year of age, twenty-two (44\%) were between 30- 49 year and eight (16\%) were of above 50 years. Questionnaires were checked for their completeness and it was found that $31(62 \%)$ were complete and $19(38 \%)$ were incomplete.

\section{Assessment of knowledge}

The first 18 questions were designed to assess the knowledge of pharmacovigilance. Out of 25 consultants, $23(92 \%)$ and all $25(100 \%)$ postgraduate students were found to be possessing adequate knowledge of pharmacovigilance. Only three $(12 \%)$ post graduate students had attended a seminar or workshop related to pharmacovigilance whereas eight $(32 \%)$ consultants had attended the same. On the question of the institutional ADR monitoring centre (AMC) site and location, only $14(56 \%)$ postgraduate students were aware of that versus $18(72 \%)$ consultants. Awareness about ADR monitoring centre was significantly lower in postgraduate students as compared to consultants. $17(68 \%)$ consultants had knowledge about ADR reporting form, from the place they collect it and tollfree number to report any ADR while only $14(56 \%)$ postgraduate students were aware of these, which was significantly lower.

The question as to who among the health care professionals are eligible to report ADRs elicited varied responses like $88 \%$ of consultants and $84 \%$ of postgraduate students opined that medical practitioners were eligible while the same figure for nurses was $(52 \%$ for consultants and $40 \%$ for postgraduate students), for pharmacists $(60 \%$ consultants and $36 \%$ postgraduate students) and for health 
workers (48\% consultants and $36 \%$ postgraduate students). Respondents also stated that patients and their relatives (44\% consultants and $20 \%$ postgraduate students) should also be allowed to report an ADR. $20(80 \%)$ consultants and $14(56 \%)$ postgraduate students were knew about serious ADR and only $12(48 \%)$ consultants and $14(56 \%)$ of postgraduate students were aware of the period for reporting an ADR. $12(48 \%)$ consultants and $10(40 \%)$ postgraduate students stated that they can report an ADR any time after it appeared. Seven out of 50 respondents stated that reporting ADR is of no value.

\section{Assessment of attitude}

Attitude of both consultants and postgraduate students towards ADR reporting were positive with all accepting that it is very important. Both groups had stated that serious suspected interactions, suspected reactions to vaccines, all suspected reactions to new drugs and serious suspected reactions to established drugs were important ADRs to be reported. The mentioned causes along with other less important causes with their average grading by both groups have been enlisted in Table 1 .

The important causes of reporting ADR stated by both groups were to ensure patient safety, to identify relatively safer drug, to identify unusual ADRs, to detect a new ADR and to identify factors which might predispose to ADR along with other reasons according to grading given by consultants and post graduate students were cited in Table 2.

Table 1: List of important ADRs to be reported with average grading given by consultants and postgraduate students.

\begin{tabular}{|lll|}
\hline \multirow{2}{*}{ Type of ADR } & A verage grading \pm SEM (range 1 to 5) \\
\cline { 2 - 3 } & Consultants & Postgraduate students \\
\hline Serious suspected interactions & $4 \pm 0.35$ & $4.64 \pm 0.13$ \\
\hline Serious suspected reactions to established drugs & $3.84 \pm 0.37$ & $4.64 \pm 0.12$ \\
\hline Suspected reactions to vaccines & $3.84 \pm 0.36$ & $4.64 \pm 0.13$ \\
\hline All suspected reactions to new drugs & $3.72 \pm 0.37$ & $4.6 \pm 0.16$ \\
\hline Suspected teratogenic effects & $3.48 \pm 0.40$ & $3.88 \pm 0.32$ \\
\hline All suspected reactions to any drug & $3.48 \pm 0.39$ & $3.64 \pm 0.15$ \\
\hline Only serious suspected reactions to new drugs & $3.12 \pm 0.42$ & $3.68 \pm 0.29$ \\
\hline Suspected reactions to herbal and nonallopathic drugs & $3.32 \pm 0.41$ & $3.64 \pm 0.26$ \\
\hline Only proven adverse reactions & $1.88 \pm 0.36$ & $3.12 \pm 0.30$ \\
\hline
\end{tabular}

Table 2: List of causes of ADR reporting (average grading by consultants and post graduate students).

\begin{tabular}{|c|c|c|}
\hline \multirow{2}{*}{ Cause for ADR reporting } & \multicolumn{2}{|c|}{ Average grading \pm SEM (range 1 to 5 ) } \\
\hline & Consultants & Postgraduate students \\
\hline To improve patient safety & $4.32 \pm 0.31$ & $4.76 \pm 0.10$ \\
\hline To identify relatively safer drug & $4.16 \pm 0.35$ & $4.2 \pm 0.20$ \\
\hline To identify unusual ADRs & $3.96 \pm 0.32$ & $4.04 \pm 0.17$ \\
\hline To identify and detect new ADR & $3.88 \pm 0.36$ & $3.64 \pm 0.24$ \\
\hline To identify factors which might predispose to ADR & $3.52 \pm 0.34$ & $4 \pm 0.20$ \\
\hline To measure the incidence of ADRs & $3.68 \pm 0.33$ & $3.68 \pm 0.22$ \\
\hline To measure the incidence of all ADRs to drugs & $3.52 \pm 0.32$ & $3.6 \pm 0.25$ \\
\hline To enable toxicity comparison for drugs in similar therapeutic classes & $3.72 \pm 0.32$ & $3.56 \pm 0.18$ \\
\hline To share information about ADRs among Colleagues & $3.76 \pm 0.33$ & $3.2 \pm 0.28$ \\
\hline To identify the disease for which drugs are prescribed & $2.92 \pm 0.38$ & $2.72 \pm 0.31$ \\
\hline To obtain information about the characteristics of particular reactions & $3.2 \pm 0.34$ & $3.68 \pm 0.22$ \\
\hline
\end{tabular}

\section{Assessment of practice}

Twenty-two (88\%) consultants and $25 \quad(100 \%)$ postgraduate students encountered 0-5 ADR per week in their practice. But only nine consultants $(36 \%)$ have reported any ADR while none of post graduate students has reported any ADR yet. But post graduate students have stated that they have discussed about ADR with their consultants and colleagues. Most commonly encountered ADRs were rashes with antimicrobials (44\%), gastritis with NSAIDs (18\%), diarrhea with amoxicillin (8\%), angioedema with ACE inhibitors $(8 \%)$ and sedation with antihistamines $(6 \%)$ etc. The factors which play important role in reporting an ADR was assessed among both groups, 
which is enlisted in Table 3. According to both groups an unusual reaction and seriousness of reaction were most common causes. The reasons for non-reporting an ADR were graded by consultants and postgraduate students and are listed in Table 4 . The common reasons cited by both groups were uncertain association (66\%), unavailability of reporting forms when needed $(76 \%)$, lack of knowledge about reporting procedure $(70 \%)$ and legal liability issues (38\%). Postgraduate students cited two more important reasons for non-reporting. They are too much time required to fill the report and they did not want to create an undue alarm while the other cause of non-reporting by consultants were reaction not clinically significant $(48 \%)$ and ADRs were well documented before marketing (38\%).

Table 3: Factors important in deciding to report an ADR.

\begin{tabular}{|lll|}
\hline Important factors & $\begin{array}{l}\text { Percentage (\%) } \\
\text { Consultants }\end{array}$ & Postgraduate students \\
\hline Unusual reaction & $96 \%$ & $80 \%$ \\
\hline Seriousness of reaction & $96 \%$ & $80 \%$ \\
\hline New product involved & $84 \%$ & $80 \%$ \\
\hline Degree of confidence in the diagnosis of the ADR & $44 \%$ & $68 \%$ \\
\hline Willing to comply with guidelines/ recommendations/advisories & $52 \%$ & $60 \%$ \\
\hline Awareness of similar reactions & $52 \%$ & $48 \%$ \\
\hline Request by a pharmaceutical manufacturer & $24 \%$ & $16 \%$ \\
\hline
\end{tabular}

Table 4: List of factors responsible for non-reporting of ADR (average grading by consultants and postgraduate students).

\begin{tabular}{|lll|}
\hline Factors responsible for non-reporting of ADR & Average grading \pm SEM (range 1 to 5) \\
\hline Reporting forms are not available when needed & Consultants & Post graduate students \\
\hline Uncertain association & $2.16 \pm 0.35$ & $4.28 \pm 0.16$ \\
\hline Ignorance about reporting procedure & $2.56 \pm 0.41$ & $3.44 \pm 0.21$ \\
\hline Legal liability issues & $2.36 \pm 0.39$ & $3.88 \pm 0.25$ \\
\hline Don't want to create undue alarm & $2.12 \pm 0.38$ & $3.12 \pm 0.23$ \\
\hline Too much time required to fill in the report & $1.32 \pm 0.26$ & $2.36 \pm 0.25$ \\
\hline Reaction not clinically significant & $1.28 \pm 0.25$ & $3.04 \pm 0.28$ \\
\hline Too busy to send an ADR report & $2.72 \pm 0.42$ & $2.92 \pm 0.28$ \\
\hline Awareness of similar reactions & $1.4 \pm 0.25$ & $2.36 \pm 0.31$ \\
\hline Doubtfulness about which ADRs should be reported & $2.8 \pm 0.38$ & $3 \pm 0.25$ \\
\hline Don't feel obliged to report & $2.08 \pm 0.33$ & $3.52 \pm 0.20$ \\
\hline Managing patients is more important than reporting ADR & $1.64 \pm 0.35$ & $2.4 \pm 0.29$ \\
\hline Would rather collect and publish personally & $1.64 \pm 0.30$ & $2.4 \pm 0.20$ \\
\hline Patient confidentiality issues & $1.56 \pm 0.30$ & $2.12 \pm 0.31$ \\
\hline Uselessness of spontaneous ADR reporting & $1.96 \pm 0.35$ & $2 \pm 0.18$ \\
\hline ADRs well documented before marketing & $1.12 \pm 0.21$ & $2.2 \pm 0.26$ \\
\hline $\begin{array}{l}\text { Think you may appear foolish to colleagues about reporting a suspected } \\
\text { reaction }\end{array}$ & $2.72 \pm 0.36$ & $2.84 \pm 0.24$ \\
\hline
\end{tabular}

Opinion was also taken from respondents about their preferred mode of reporting an ADR. All twenty-five $(100 \%)$ consultants and seventeen $(68 \%)$ of post graduate students opted the reporting via ADR reporting forms.

Two (8\%) consultants and five (20\%) postgraduate students preferred mail via internet and $12 \%$ of consultants and $16 \%$ of postgraduate students wanted to do it by a phone call to drug company.

\section{DISCUSSION}

This study was a questionnaire-based study, which included consultants and postgraduate students of a tertiary care teaching hospital, V.S.S. Institute of Medical Sciences and Research, Burla, Odisha. This study was done to assess the knowledge, attitude and practice of prescribers towards ADR reporting. Indian studies at Mumbai, Mysore and Muzaffarnagar have shown high knowledge, but poor practice for ADR, among prescribers. ${ }^{8,12,13}$ One more study 
conducted in Civil hospital, Ahmedabad have shown not only poor practice, but also inadequate knowledge. ${ }^{11}$ The average knowledge score of respondents was $38 \%$ in study conducted in Ahmedabad. ${ }^{11}$ In present study only $28 \%$ of prescribers were found to be with adequate knowledge, $38 \%$ were having average knowledge and $34 \%$ had poor knowledge. The cause for this may be because many of them have not attended any seminar or workshop related to pharmacovigilance, indicating the need of such type of awareness program about pharmacovigilance in institute.

The percentage of response $(71.4 \%)$ was found to be higher as compared to study conducted in London $(57 \%)$, Italy $(59.1 \%)$ and India $(61 \%)$ but lower than in Netherlands (72.7\%). 6,11,14,15 This may be because present study was consisting small study population from a teaching hospital, where faculties were easily available. In this study, the response rate of consultants was higher than postgraduate students as compared to study conducted in Ahmedabad, where response rate of postgraduate students were higher than consultants. ${ }^{11}$ The reason for these may be less awareness and lack of knowledge about the importance of pharmacovigilance among postgraduate students. The average grading score of 2.4 out of 5 was also given by postgraduate students that they don't feel obliged to report an ADR. These showed the lack of awareness about importance of pharmacovigilance among them. This might be due to their feeling that they are students and so, need not practice pharmacovigilance. The attitude of prescribers towards ADR reporting was good but actual practice was very poor, as all the respondents stated that reporting an ADR was very important and most of them also encountered 0-5 ADR per week. It showed that they were aware of adverse reactions and were vigilant also, but actual reporting rate was very low. Only $36 \%$ of prescribers have reported any ADR yet, although this is higher than study conducted at Ahmedabad, where only $15 \%$ of respondents had reported any ADR. ${ }^{11}$ The reasons for reporting ADRs, as reported by Chetna et al, were to improve patient safety and identifying new ADRs. ${ }^{11}$ In the present study also, the reasons for reporting ADRs were to improve patient safety, to identify relatively safer drugs, to detect an unusual ADR and to identify new ADRs.

The reasons for under- reporting of ADRs have been summarized by Inman as the "seven deadly sins". ${ }^{16}$ This includes financial incentives (rewards for reporting), legal aspects (fear of litigation), complacency (belief that the serious ADRs are already documented when a drug is introduced in the market), diffidence (belief that reporting should be done when there is certainty that the reaction is caused by the use of a particular drug), indifference (belief that a single report would make no difference), ignorance (that only serious ADRs are to be reported), lethargy (excuses about lack of time or disinterestedness). ${ }^{12}$ Some of these sins were also documented in Mysore, Mumbai, and Muzaffarnagar. ${ }^{8,12,13}$ In present study, the most common cause for non- reporting were unavailability of reporting forms when needed, uncertain association, ignorance about the reporting system and doubtfulness about which ADRs should be reported. In present study also, some of the Inman's "seven deadly sins" were found, of which legal aspects, complacency and diffidence were most important while the lack of financial incentives was least common cause. These suggested the essential need of pharmacovigilance awareness program. Ignorance about reporting was more evident among post graduate students as compared to consultants.

Spontaneous reporting of ADRs by patients and healthcare personnel, other than doctors, is practiced in many parts of the world. ${ }^{17-19}$ In present study, about $86 \%$ of respondents answered that medical practitioners were eligible for ADR reporting while only $36 \%$ respondents stated that patients could also report an ADR. Similar kind of finding was also observed in study conducted by Chetna et al, where less than half of the respondents opined that nurses, pharmacists and dentists were eligible for ADR reporting. ${ }^{11}$ Many of our respondents also were not aware about that what happened with their reported $\mathrm{ADR}, 30 \%$ of them opined that they are sent to State Health Department for further action and $24 \%$ opined that they have been sent to Dean and Medical Superintendent of the institute along with National ADR monitoring centre. These are the important lacunas of knowledge related to ADR reporting, we have found in our study. Once they come to know the fate of these reports, it would generate interest among them to report ADRs. These can be overcome by educational interventions, feedback to reported ADRs and professional support by Pharmacologists in reporting and managing ADRs.

\section{CONCLUSION}

The present study pointed out the lack of knowledge and awareness among healthcare professionals as regards pharmacovigilance in our hospital which was the important cause of under-reporting. The doctors, pharmacists and nurses have a great responsibility in reporting ADRs and strengthening the pharmacovigilance system. Our findings may prove to be useful for health authorities and policy makers for future evaluation and educational initiatives for improving pharmacovigilance and ADR reporting in hospitals.

\section{ACKNOWLEDGEMENTS}

Authors are thankful to all consultants and resident doctors who were enrolled in the study for their co-operation in conducting the study.

Funding: No funding sources

Conflict of interest: None declared

Ethical approval: Not required

\section{REFERENCES}

1. Singhal KC. Pharmacovigilance in India -the birth of a professional society. J Pharmacovigilance Drug Safety. 2015 Oct-Dec;12(4):1-3. 
2. Participation of nursing professionals in pharmacovigilance. Role of Nurses as ADR Reporter in PvPI. Pharmacovigilance Programme India Newslet. 2014 Aug; 4(9):2.

3. Siddiqui $\mathrm{Z}$, Mahr k. India drug monitoring programme struggles to grow fast enough. 2016 Feb 16. Available at: in.reuters.com/article/india-health-drugsidINKCNOVO2HI.

4. Montastruc JL, Sommet A, Lacroix I, Olivier P, Durrieu G, Damase-Michel C, et al. Pharmacovigilance for evaluating adverse drug reactions: Value, organization, and methods. Joint Bone Spine. 2006;73:629-32.

5. Edwards IR, Aronson JK. Adverse drug reactions: definitions, diagnosis, and management. Lancet. 2000;356(9237):1255-9.

6. Cosentino M, Leoni O, Banfi F, Lecchini S, Frigo G. Attitudes to adverse drug reaction reporting by medical practitioners in a Northern Italian district. Pharmacological Res. 1997 Feb 1;35(2):85-8.

7. Rehan HS, Vasudev K, Tripathi CD. Adverse drug reaction monitoring: knowledge, attitude and practices of medical students and prescribers. National Med J India. 2002 Jan 1;15(1):24-6.

8. Gupta P, Udupa A. Adverse drug reaction reporting and pharmacovigilance: Knowledge, attitudes and perceptions amongst resident doctors. J Pharmaceut Sci Res. 2011 Feb 1;3(2): 1064-9.

9. Subish P, Izham MM, Mishra P. Evaluation of the knowledge, attitude and practices on adverse drug reactions and pharmacovigilance among healthcare professionals in a Nepalese hospital: a preliminary study. Internet J Pharmacol. 2008;6:1.

10. Olsson S. Using medicines? get informed. stay alert.be safe. The $15^{\text {th }}$ annual conference and international colloquium on patient safety, Kolkata, India; 2015 Oct-Nov:18-21.

11. Desai CK, Iyer G, Panchal J, Shah S, Dikshit RK. An evaluation of knowledge, attitude, and practice of adverse drug reaction reporting among prescribers at a tertiary care hospital. Perspect Clin Res. 2011 OctDec; 2(4):129-36.
12. Ramesh M, Parthasarathi G. Adverse drug reactions reporting: attitudes and perceptions of medical practitioners. Asian J Pharm Clin Res. 2009 Apr;2(2):10-4.

13. Ghosh S, Ali S, Chhabra L, Prasad C, Gupta A. Investigation of attitudes and perception of medical practitioners on adverse drug reaction reporting-a pilot study. T Ph Res. 2010;3(6):1-9.

14. Belton KJ, Lewis SC, Payne S, Rawlins MD, Wood SM. Attitudinal survey of adverse drug reaction reporting by medical practitioners in the United Kingdom. Br J Clin Pharmacol. 1995 Mar;39(3):2236.

15. Grootheest V. Attitudinal survey of voluntary reporting of adverse drug reactions. $\mathrm{Br} \mathrm{J}$ Clin Pharmacol. 1999 Oct;48(4):623-7.

16. Inman WH. Attitudes to adverse drug reaction reporting. Br J Clin Pharmacol. 1996 May $1 ; 41(5): 434-5$.

17. Van Grootheest AC, Van Puijenbroek EP, de Jong-van den Berg LT. Contribution of pharmacists to the reporting of adverse drug reactions. Pharmacoepidemiol Drug Safety. 2002 Apr 1;11(3):205-10.

18. De Langen J, van Hunsel F, Passier A, de Jongvan den Berg LT, van Grootheest K. Adverse drug reaction reporting by patients in the Netherlands. Three years of experience. Drug safety. 2008;31:515-24.

19. Morrison-Griffiths S, Walley TJ, Park BK, Breckenridge AM, Pirmohamed M. Reporting of adverse drug reactions by nurses. Lancet. $2003 \mathrm{Apr}$ 19;361(9366):1347-8.

Cite this article as: Saha K, Rath B, Agrawal R. A survey of knowledge, attitude and practice of adverse drug reaction monitoring among doctors in Western Odisha region. Int J Basic Clin Pharmacol 2018;7:2234-9. 